ISSN: 1980-055X

\title{
AS CIDADES E A PRECIPITAÇÃO UMA RELAÇÃO DEMASIADO BRIGUENTA
}

\author{
Ana Monteiro ${ }^{1}$
}

\begin{abstract}
RESUMO
A Grande Área Metropolitana do Porto (GAMP) é um excelente testemunho da desvalorização do contexto climático assumida pelos fazedores de tecido urbano nas últimas três décadas. Apesar das surpresas, frequentemente negativas, com que o sistema climático foi presenteando os cidadãos, estes, continuam a investir muito mais recursos na busca de instrumentos de controlo do que em meios para promover uma convivialidade harmoniosa. Os anos de 2000-01 e 2004-05 são dois exemplos igualmente dramáticos e incompreendidos mas de índole diversa que servem para mostrar como os cidadãos urbanos se relacionam mal com a irregularidade da precipitação. Pretende-se mostrar que enquanto estas expressividades do sistema climático - a precipitação intensa ou a seca - não forem mecanicamente compreendidas dificilmente serão percebidas. E, continuarão a ser desvalorizadas em qualquer processo de decisão (individual ou colectivo). Ao ignorar o sistema climático, o desenho urbano acrescenta vulnerabilidade a uma equação (evento x vulnerabilidade) onde temos de acreditar que só conseguimos controlar um dos seus termos.
\end{abstract}

\section{ABSTRACT}

The Porto Greater Metropolitan Area (GAMP) is an excellent evidence of the depreciation of the climate context taken by urban planners in the last three decades. Despite the numerous surprises, often negative, given to citizens by the climate system, they insist in spending more resources in the research of means of command, control and intervention than on ways of promoting a healthy harmony among human expectations and climate system behaviour. The years of 2000-01 and 2004-05 are two dramatically examples of diverse nature that serves to show how the urban citizens are badly related with the irregularity of the precipitation. We intend to show that while these climatic system's expressions - the intense precipitation or drought - are not mechanically understood they will hardly be perceived. They will continue to be forgotten in any decision process (individual or collective). And if we ignore the climatic system in planning we add vulnerability to an equation (event $x$ vulnerability) where we only have control upon one of its terms.

${ }^{1}$ Departamento de Geografia, FLUP, Via Panorâmica s/no, 4150-564 Porto Telef. 226077145; Fax 226077150, anamonteirosousa@gmail.com 


\section{INTRODUÇÃO}

É já muito difícil imaginar algum lugar à superfície da Terra isento de risco porque a ecúmena ampliou-se, substantivamente, nas últimas décadas surgindo aglomerações urbanas em contextos geográficos impensáveis até há poucas décadas. Por esse motivo, é natural que um número crescente de cidadãos urbanos se sinta frequentemente bastante ameaçado, nomeadamente, pela conduta indesejável da temperatura, da precipitação, do vento, etc.. Ameaças, que cada vez mais transformam, os tecidos urbanos, em cenários caóticos e quantas vezes catastróficos. Al Gore no seu documentário "Uma Verdade Inconveniente" diz mesmo que "...a Natureza está a enlouquecer (...) e estamos a entrar na era das consequências...". Afirmação que testemunha o modo como tem sido tão interiorizada a ideia que a culpa das catástrofes com que vamos sendo confrontados é, sobretudo, do clima. Senão vejamos quantas vezes lemos e comentamos: "a precipitação causou prejuízos...", "a onda de calor matou ...", "ciclone ceifou...", " a tromba de água destruiu ...".

É neste quadro de referência em que o sujeito é frequentemente o clima que pretendemos discutir a noção de risco e catástrofe climática em espaços urbanos. Gostaríamos de sublinhar a inocência do sistema climático na maioria dos casos e vincar a enorme responsabilidade do incremento da vulnerabilidade em cidades que são cada vez muito mais arte do que natureza.

\section{Paroxismos, riscos climáticos e vulnerabilidade em espaço urbano}

A interpretação dos riscos climáticos a que estamos sujeitos em espaços urbanos é muito variada e controversa. Sendo o risco ${ }^{2}$ - risk - uma medida da probabilidade e da intensidade do perigo ${ }^{3}$ (Tobin, 1997, p.282), compreende-se que nos espaços urbanos a panóplia de processos ou eventos - hazard potencialmente geradores de perdas aumentou à medida que o suporte biogeofísico foi sendo omitido no desenho urbano.

$\mathrm{E}$, este alheamento progressivo do modus vivendi urbano relativamente a todas as componentes do ecossistema nomeadamente ao sistema climático, diminuiu a capacidade de antecipar, lutar, resistir e recuperar dos impactes

\footnotetext{
2 Para explicar a diferença entre risk e hazard, alguns autores socorrem-se do exemplo de duas pessoas a atravessar o oceano: uma numa embarcação a remo, outra num barco a motor. Em ambos os casos o principal hazard é a profundidade do oceano e a elevada ondulação enquanto que o risk é a probabilidade de se afundarem. Para a maioria dos autores anglo-saxónicos, risk é a probabilidade espacial e temporal da ocorrência de um acontecimento que poderá originar consequências negativas, enquanto que hazard significa algo de aleatório, ocasional, que não se pode prever e que afecta diferentes locais, isoladamente ou em conjunto, em diversos momentos. Este último conceito foi traduzido na bibliografia francófona pelo termo áleas.

3 Segundo Vilela (2002) o substantivo risco deriva do verbo latim resecare que significa "cortar separando" correspondendo na actualidade "à possibilidade de um acontecimento futuro e incerto"; "possibilidade de inconveniente ou fatalidade". O substantivo «perigo» provém da palavra latina "periculosu", e significa "situação que ameaça a existência de uma pessoa ou coisa"; "circunstância que prenuncia um mal para alguém ou para alguma coisa", "estado ou situação que inspira cuidado ou gravidade"3; "Aquilo que constitui uma ameaça, que compromete a segurança, a saúde, o bemestar das pessoas ou o desaparecimento de alguma coisa".

Segundo o mesmo autor, tratam-se de esquemas imagéticos diferentes: a palavra risco está primeiro que perigo, dado que «risco» se situa numa posição ainda de segurança, embora haja probabilidade de algo ocorrer enquanto «perigo» pressupõe maior proximidade da situação de ruptura.
}

8

Setembro-2009 
negativos gerados por episódios de precipitação intensa, temperaturas elevadas ou muito baixas, ventos velozes, etc.. Em suma, a vulnerabilidade das cidades aos riscos climáticos tem crescido na proporção directa da alienação do desenho urbano face ao sítio e à posição geográfica.

A tolerância e a elasticidade social, económica e política a um episódio climático extremo condicionam a gravidade do risco já que ele é a função multiplicativa do episódio pela vulnerabilidade. Assim, se não houver vulnerabilidade, ou se esta for muito fraca, não há risco ainda que ocorram paroxismos climáticos (Figura 1). Contudo, episódios vulgares e frequentes podem gerar consequências graves se a vulnerabilidade individual e colectiva aumentar.

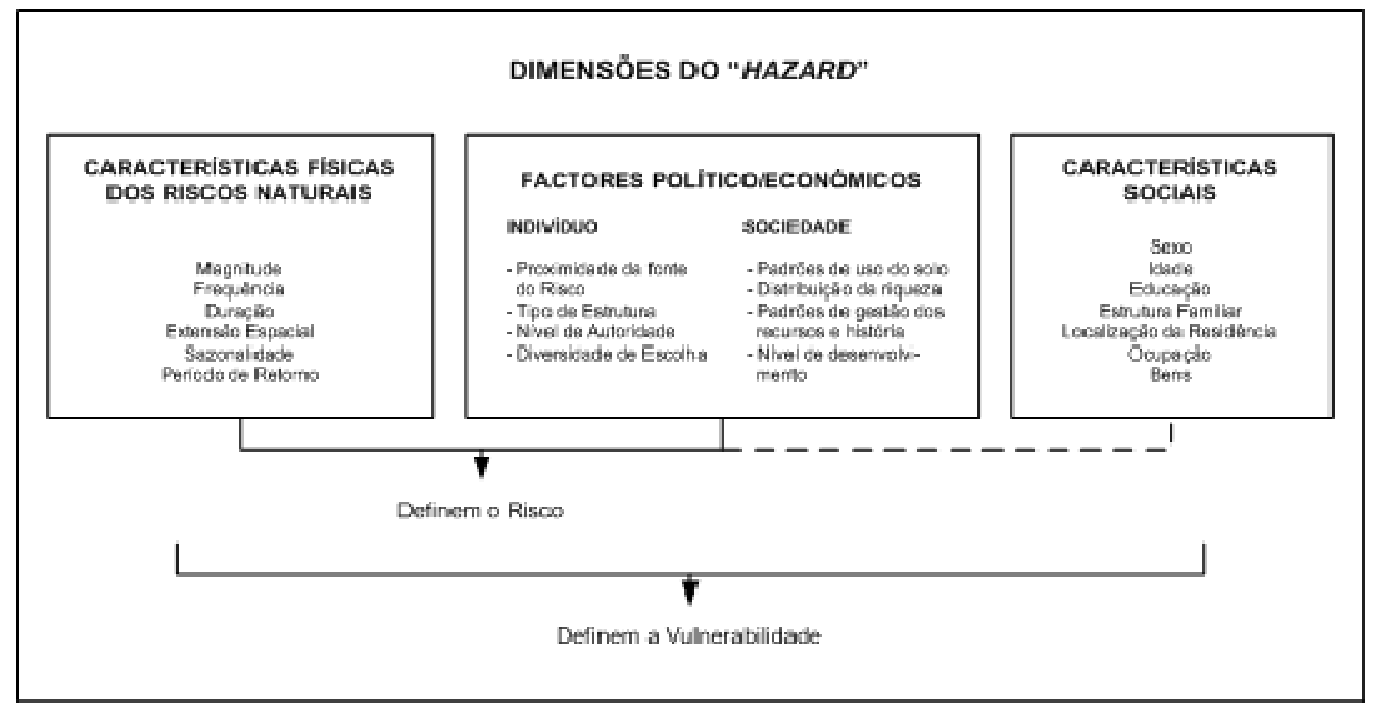

Figura 1. Variáveis intervenientes na definição de risco e vulnerabilidade (adaptado de TOBIN, 1997, p. 324).

Apesar dos riscos climáticos serem, maioritariamente, naturais, involuntários e localizados (Figura 2 e Quadro I), a concretização do risco catástrofe - e a sua magnitude e gravidade depende da tolerância da sociedade face aos impactes negativos gerados. Por isso, nem sempre o risco real e o percebido coincidem.

Nas cidades, a avaliação qualitativa dos impactes é muito mais importante do que a quantitativa. As pessoas tendem a avaliar os riscos multidimensionalmente, mas de forma subjectiva, fazendo com que alguns sejam socialmente ampliados, enquanto outros são incompreensivelmente desvalorizados (Figura 3).

Nos espaços urbanos a excessiva crença na ciência e na tecnologia para moldar o suporte biogeofísico aliada ao predomínio de vivências indoor, tem dificultado a observação e o armazenamento de informações sobre o sistema climático. As respostas, consequência do modo como o risco é percebido e avaliado, traduzem precisamente esta grande incapacidade dos cidadãos urbanos para lidarem com os riscos climáticos apesar de confrontados com um número cada vez maior de impactes negativos (Quadro I). 
Natural

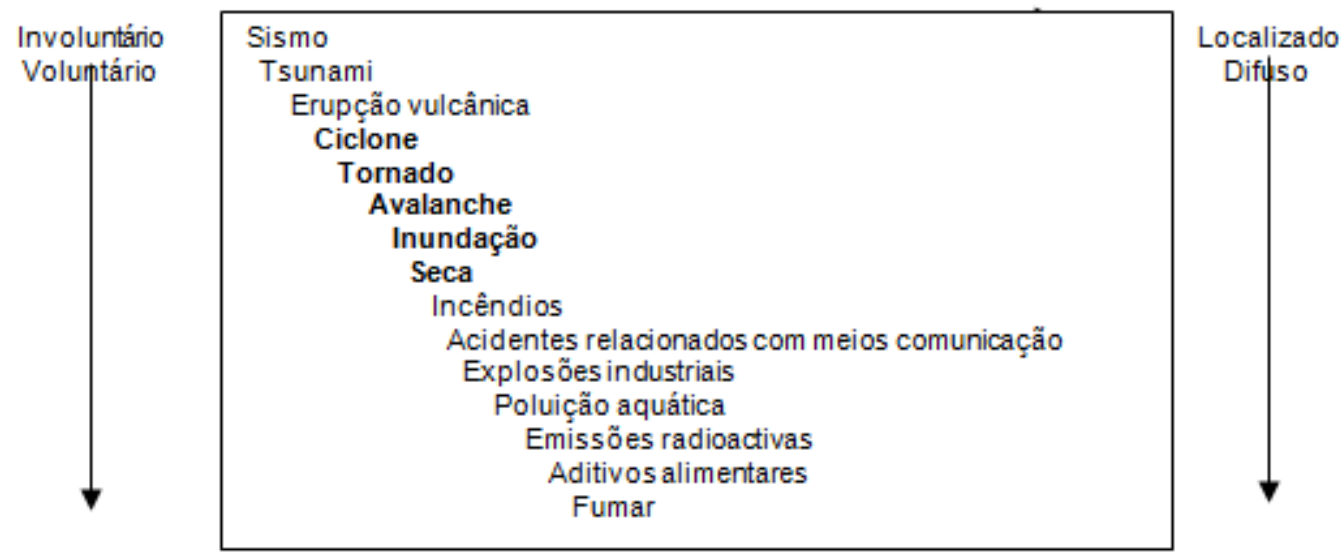

Figura 2. Riscos ambientais (adaptado de SMITH, 1992, p. 16).

\begin{tabular}{|l|c|c|}
\hline Evento & Número & Percentagem \\
\hline Inundação & 456 & 33 \\
\hline Ciclone Tropical & 298 & 21 \\
\hline Seca & 205 & 15 \\
\hline Sismo & 133 & 10 \\
\hline Tempestade & 115 & 8 \\
\hline Movimentos de Massa & 65 & 5 \\
\hline Onda Calor & 29 & 2 \\
\hline Vaga Frio & 28 & 2 \\
\hline Erupção Vulcânica & 23 & 2 \\
\hline Avalanche & 10 & 1 \\
\hline Tsunami & 10 & 1 \\
\hline Incêndio Florestal & 6 & 0 \\
\hline Proliferação de Insectos & 2 & 0 \\
\hline Total & $\mathbf{1 3 8 0}$ & $\mathbf{1 0 0}$ \\
\hline
\end{tabular}

Quadro I. Totais globais dos principiais tipos de catástrofes naturais do CRED entre 1964-98 (adaptado de SMITH, 1992, p.34).

Apesar do risco climático objectivo evidenciar a necessidade de outras opções de desenho urbano (ex: menor área impermeabilizado, menor artificialização dos cursos de água, volumetrias menores, maior heterogeneidade de materiais, etc.), a sociedade julga que a tecnologia é capaz de a proteger de todos os tipos de expressões do sistema climático (Mileti, 1999). Por isso, a persistente desvalorização dos hazards climáticos tem contribuído para incrementar a sua vulnerabilidade, acrescentando danos e perdas perfeitamente evitáveis. 


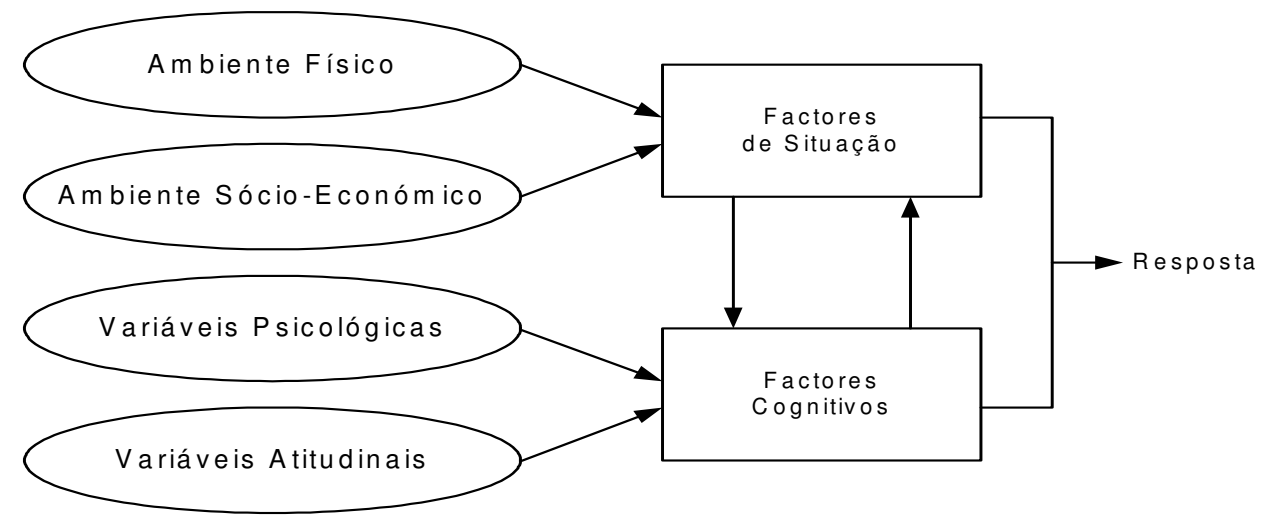

Figura 3. Factores da Percepção do Risco (adaptado de TOBIN, 1997, p. 149).

A concentração, nas cidades, de uma panóplia de actividades e de pessoas faz com que cada complexo psico-sócio-económico avalie, perceba e exija do sítio e do sistema climático desempenhos muito diversos. Coexistem, nos espaços urbanos, grupos muito diversos no que respeita à avaliação e percepção do riscos em geral e dos climáticos em particular. Uma parte substantiva da população urbana, geralmente os de menor capacidade económica, têm uma fraca tolerância económica e social à impulsividade do sistema climático. Por isso, estão expostos demasiadas vezes no sítio e no momento errados (Fig.4).

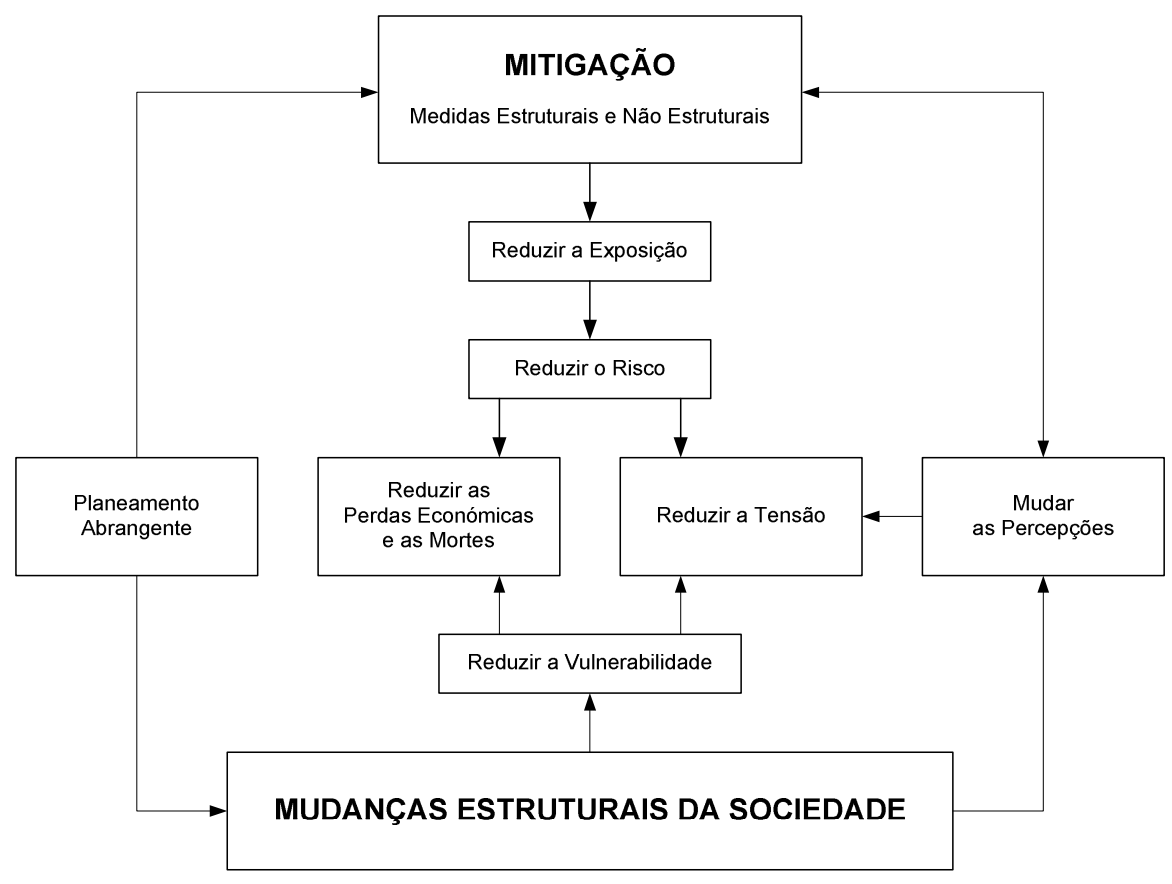

Figura 4. Modelo de mitigação (adaptado de TOBIN, 1997, p. 340.)

A redução da vulnerabilidade da população urbana ao comportamento do sistema climático exige mudanças estruturais na sociedade que promovam um relacionamento mais atento e mais humilde. De pouco serve culpabilizar o clima 
pelos danos e perdas durante os episódios inesperados, ou melhor, indesejados. Catapultar para o divino ou atribuir a responsabilidade ao sistema climático pode aliviar temporariamente a tensão mas não auxilia os fazedores urbanos a reduzir a exposição aos perigos (Figura 5). E isso só se consegue com uma mudança estrutural nos paradigmas de desenho urbano excessivamente crentes nos milagres da ciência, da técnica e da energia barata.

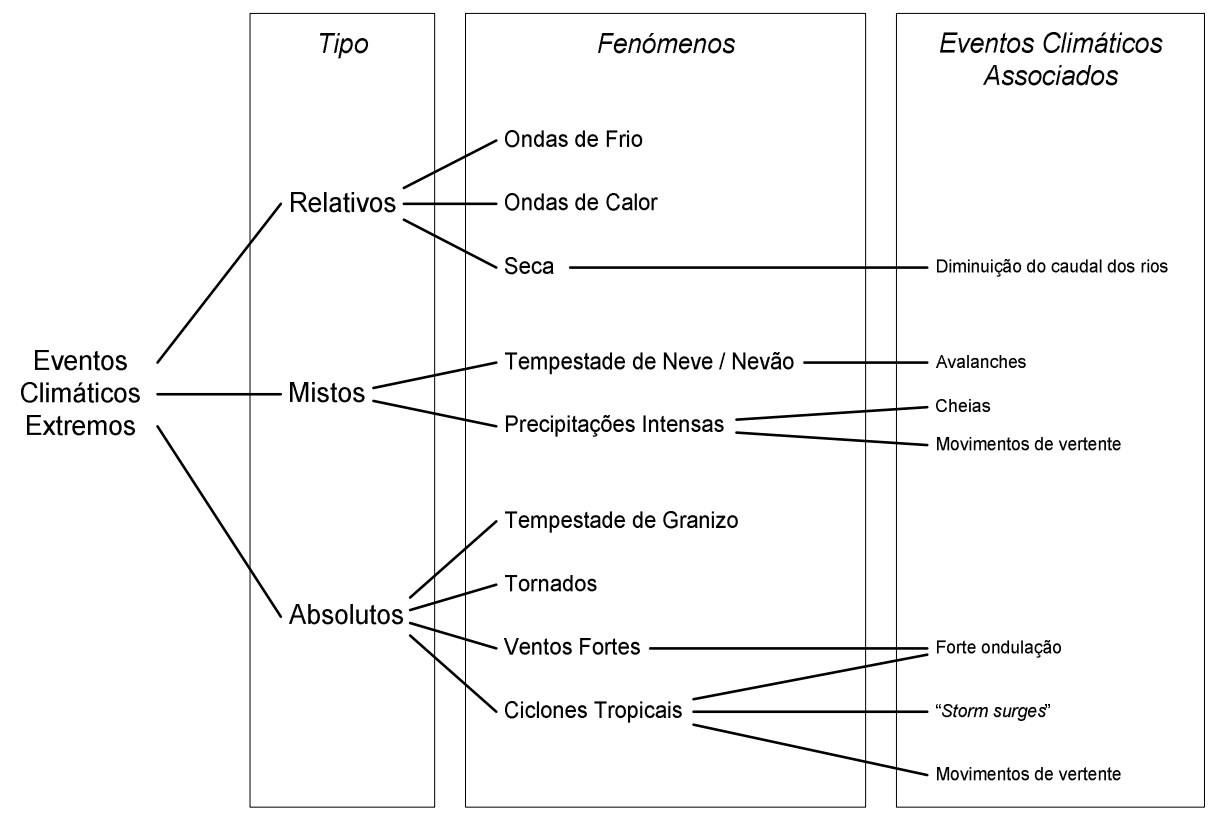

Figura 5. Classificação dos acontecimentos climáticos extremos (adaptado de WALSH, 1999, p. 52).

\section{A precipitação - um dos riscos mais indesejados em meio urbano}

Sabendo que os riscos climáticos são responsáveis por cerca de $80 \%$ das perdas materiais e humanas (Mileti, 1999), e que em espaço urbano, são excepcionalmente amplificados e geradores de caos e stress, elegemos, a título de exemplo, analisar dois episódios catastróficos protagonizados pelo comportamento da precipitação no Porto neste início do século XXI (2000-01; 2004-05). Escolhemos estes dois episódios porque nos parecem paradigmáticos da complexidade do caldo analítico individual e de grupo que despoleta cenários catastróficos.

Dentre o grupo de paroxismos climáticos que afectam a vitalidade urbana, a precipitação é um bom exemplo do(s) enviesamento(s) analíticos que vingam na relação estreita existente entre a vulnerabilidade criada e a dimensão dos danos causados.

A precipitação é um elemento climático fundamental para a vida nas suas diversas formas mas também é responsável por elevados prejuízos consoante a natureza, a intensidade e a duração do episódio. A sua presença ou a sua escassez é responsável, actualmente, por prejuízos avultados sobretudo em espaços densamente ocupados. 
No nosso contexto climático - temperado mediterrânico - a irregularidade da precipitação pode gerar situações muito críticas em espaço urbano tanto se for concentrada e intensa como se for escassa.

Escolhemos este elemento climático precisamente por esta característica intrínseca no nosso contexto climático - a irregularidade. É que urge compreender porque é que sendo a irregularidade da precipitação uma das principais características, continuamos a ser constantemente surpreendidos sempre que ela escasseia ou quando ocorre com grande frequência e intensidade.

Vejamos a este propósito como os registos seculares da estação climatológica do Porto Serra do Pilar ilustram bem a irregularidade com que a precipitação tem brindado a região portuense (Figuras 6 e 7).

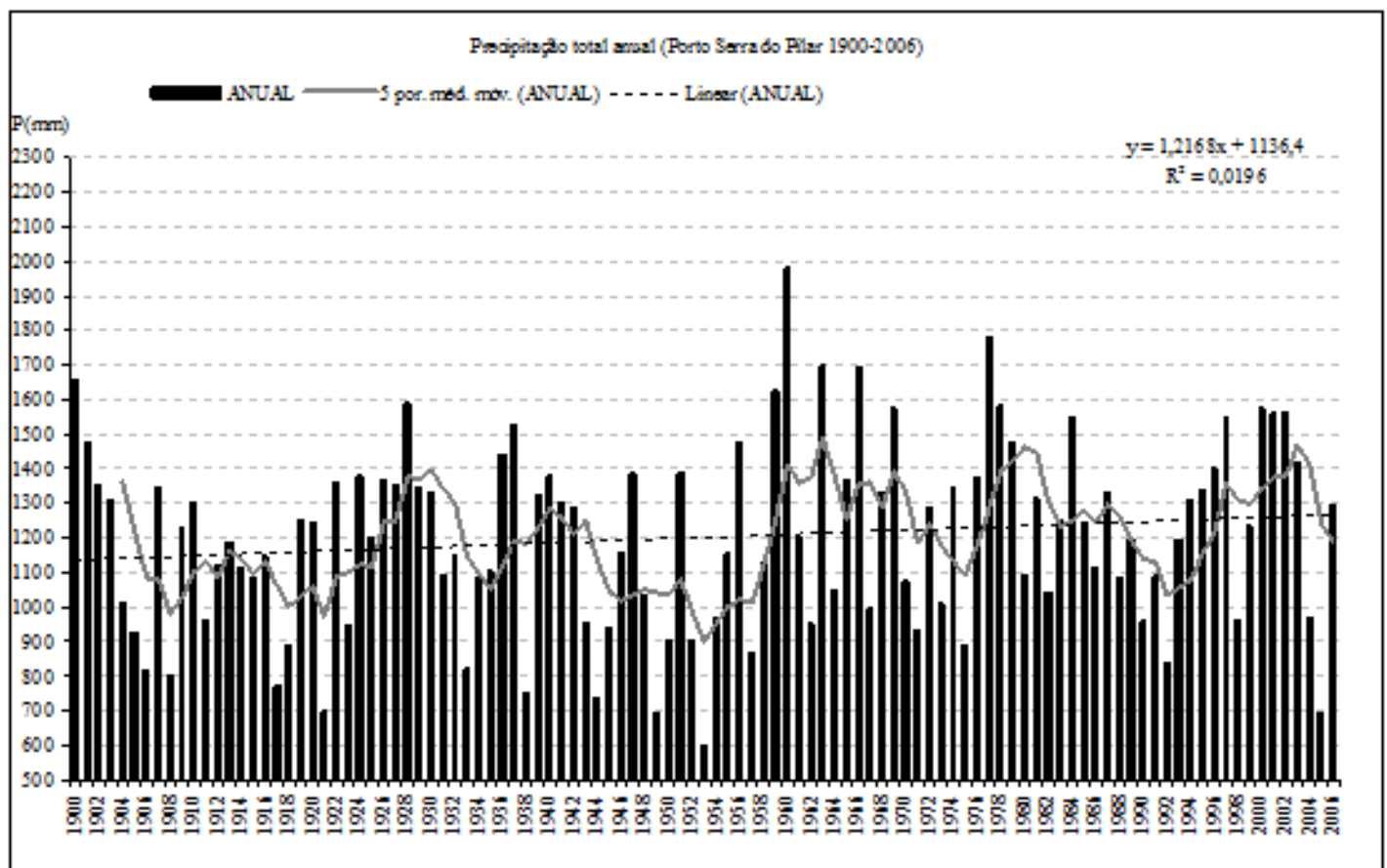

Figura 6. Precipitação total anual no Porto-Serra do Pilar (1900-2006).

A precipitação, quando ocorre com grande intensidade e sobretudo quando se Ihe associam inundações rápidas - flash floods - em rios e ribeiros artificializados, pode paralisar completamente uma cidade. Estes movimentos rápidos de água e massa podem atingir grandes velocidades ( $>6 \mathrm{~m} / \mathrm{s})$ e arrastar consigo pessoas e bens.

Quando rareia, a água, provoca também, nos espaços urbanizados, impactes negativos de grande magnitude ao nível da compactação do solo geradora de rupturas nos edifícios e infra estruturas, do abastecimento de água e do saneamento, da saúde pública, etc. 


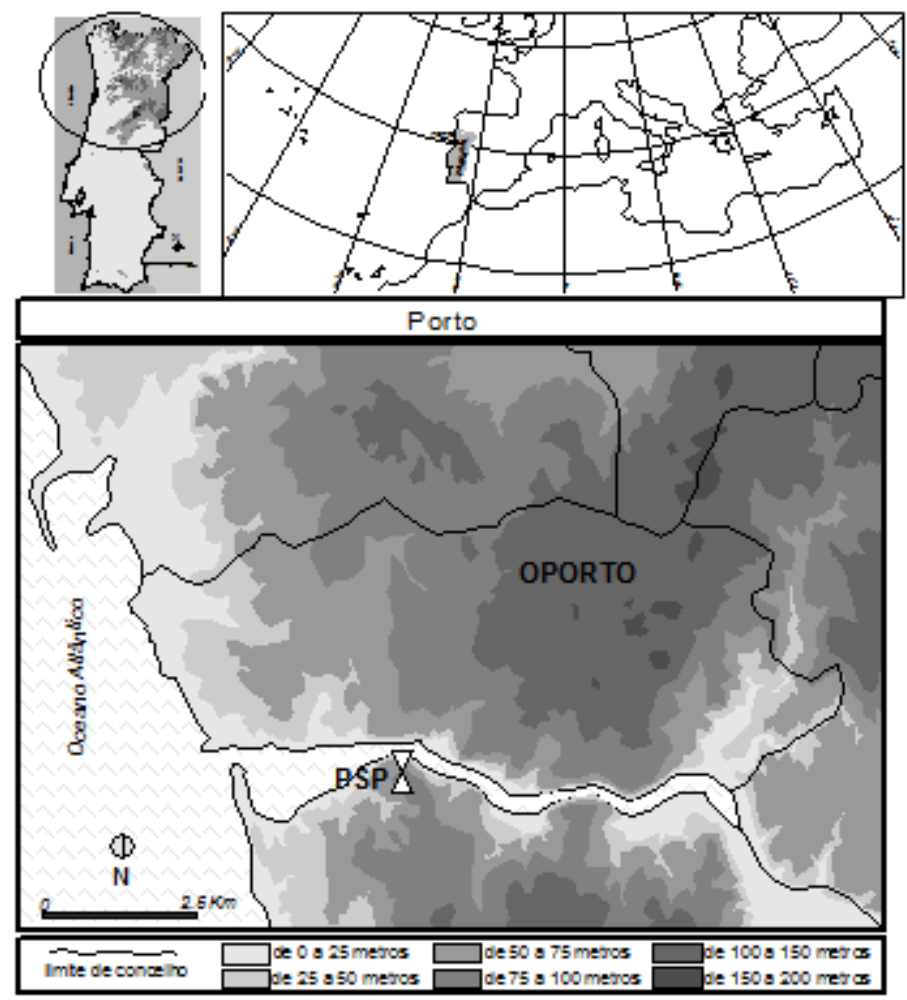

Figura 7. Localização geográfica da estação de Porto-Serra do Pilar.

\section{O Inverno 2000-2001 e a seca de 2004 no Porto - paroxismo ou vulnerabilidade acrescida?}

Os Invernos de 2000-2001 e de 2004-2005 foram, no Porto, dois exemplos da gravidade dos impactes provocados pela precipitação. Enquanto no primeiro caso a catástrofe acontece porque 0 episódio chuvoso foi excepcionalmente elevado à escala do século, no segundo a magnitude dos danos deve-se à ausência prolongada de precipitação (Figura 8).

Com este contributo, gostaríamos de ajudar a avaliar a efectiva "excepcionalidade" destes episódios mas, simultaneamente, aproveitar para reflectir sobre a perigosidade acrescida pelas modernas opções de planeamento.

Pretendemos demonstrar que o actual desenho urbano ignora o sítio e a posição geográfica, limitando-se a replicar modelos de qualquer latitude e aumentando, com isso, as causas de progressão da vulnerabilidade que transformam, por exemplo, alguns episódios chuvosos absolutamente vulgares em catástrofes. 


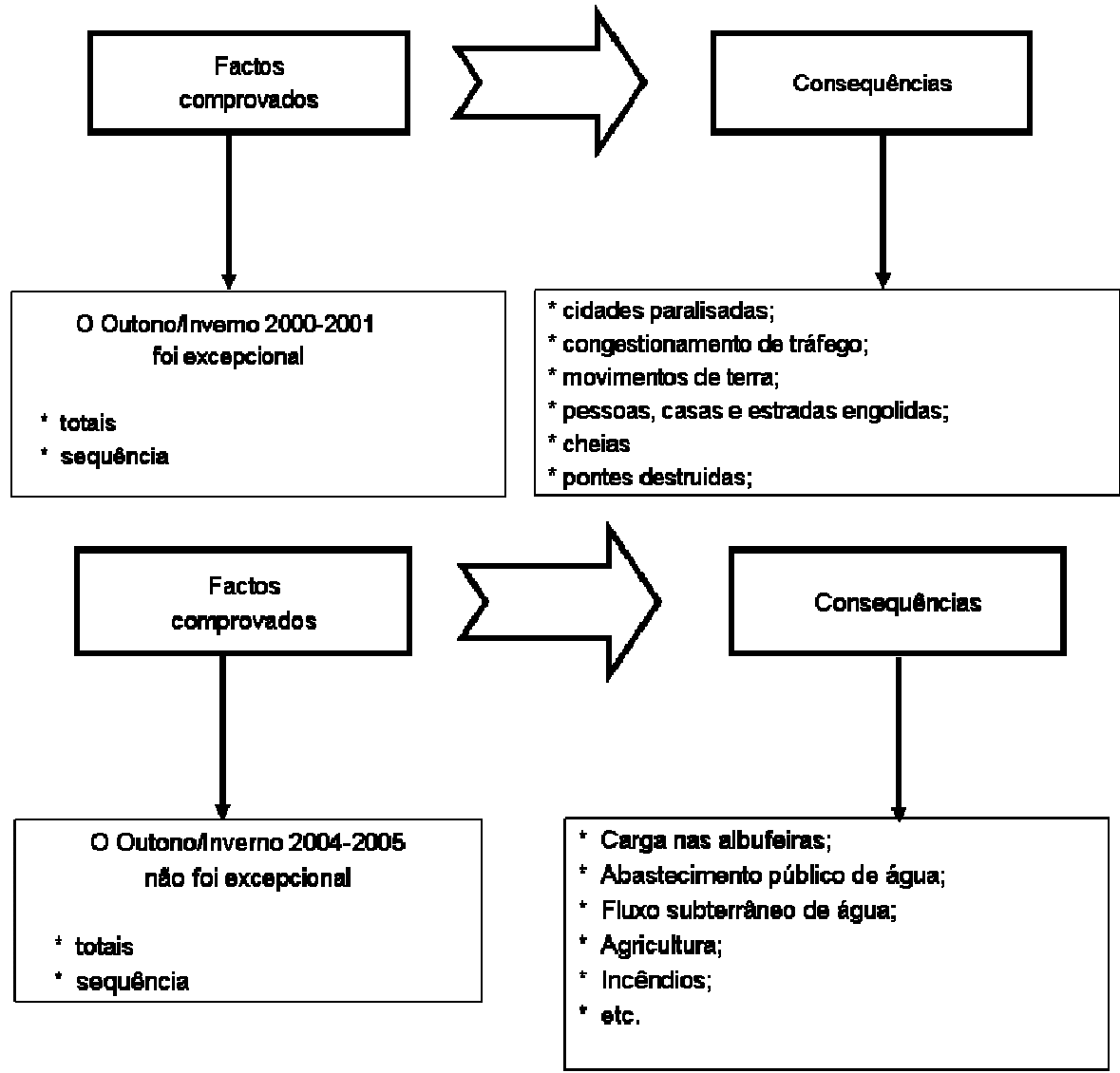

Figura 8. A relação entre a dimensão da catástrofe, a excepcionalidade do comportamento da precipitação e a vulnerabilidade.

\section{O Inverno de 2000-2001}

A precipitação intensa e frequentemente registada no norte e centro de Portugal entre Novembro de 2000 e Março de 2001 (Figuras 9, 10 e 11), paralisou várias cidades e provocou o deslizamento de terras engolindo pessoas, casas e estradas. Os rios transbordaram das suas margens e as pontes desabaram arrastando consigo veículos em circulação e afogando dezenas de pessoas. E, a explicação para todas as catástrofes foi endereçada para o "mau tempo" e para a "excepcional" duração e intensidade da precipitação.

Entre Outubro de 2000 e Março de 2001 acumulou-se o maior total de precipitação do século (Figura 10). Durante os meses, habitualmente, mais chuvosos do ano, atingiu-se, pela primeira vez desde que há registos no Porto Serra do Pilar, mais de 1700 mm de precipitação (Figura 10).

Comparativamente com os totais mensais mais elevados do século, Janeiro e Março de 2001 foram, no Porto SP, os mais chuvosos de sempre (Figura 11). Destes dois, destaca-se, principalmente, Março de 2001 que foi excepcional no total de precipitação que acumulou (Figura 12). Até 2001, o total mensal de precipitação mais elevado havia sido 359,5 mm (Março de 1947). Os $587,4 \mathrm{~mm}$ de chuva totalizados em Março de 2001 ultrapassaram em mais de $60 \%$ o valor, até então, mais elevado do século. 

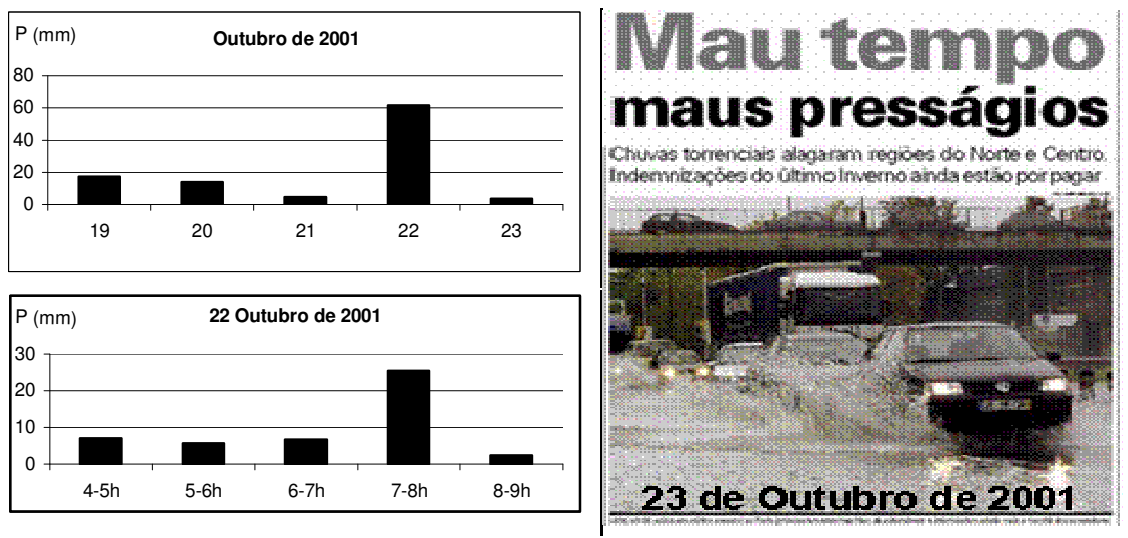

Figura 9. Exemplo dos efeitos na circulação dentro da cidade do Porto causados por um episódio chuvoso particularmente intenso entre as 7-8h.

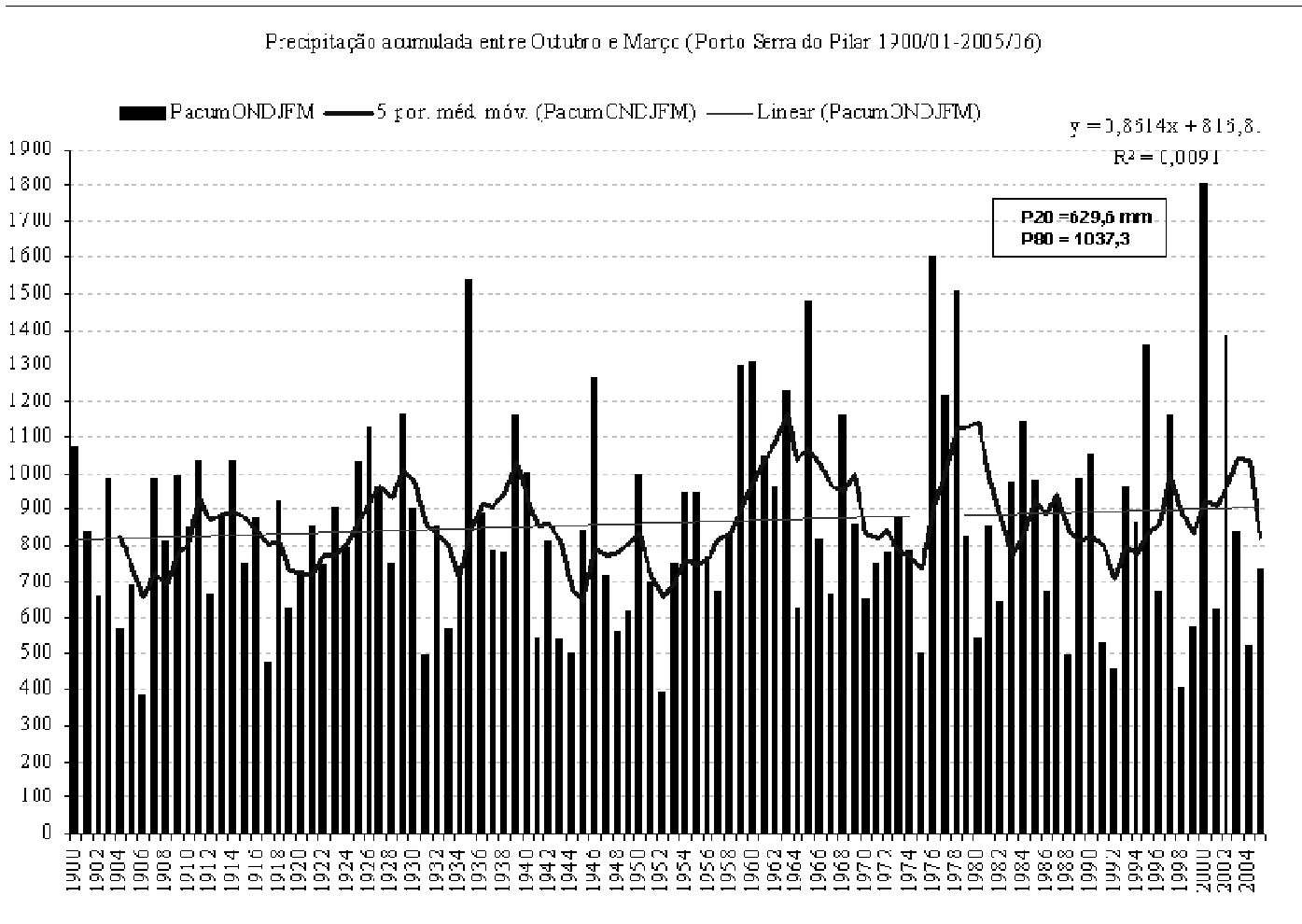

Figura 10. Precipitação acumulada entre Outubro e Março no Porto-Serra do Pilar (1900-2005).

Para além de ter observado os totais mensais de precipitação de Janeiro e Março mais elevados de que há memória (Figura 12), o Outono/Inverno 20002001, caracterizou-se também, pela maior sequência de dias com precipitação do século (Figura 13). Durante este período, choveu mais de 4 em cada 5 dias. Excluindo Fevereiro, que correspondeu a um intervalo na sequência, quase interminável, de dias com chuva, todos os outros meses registaram apenas 1,2 ou 3 dias sem precipitação. 


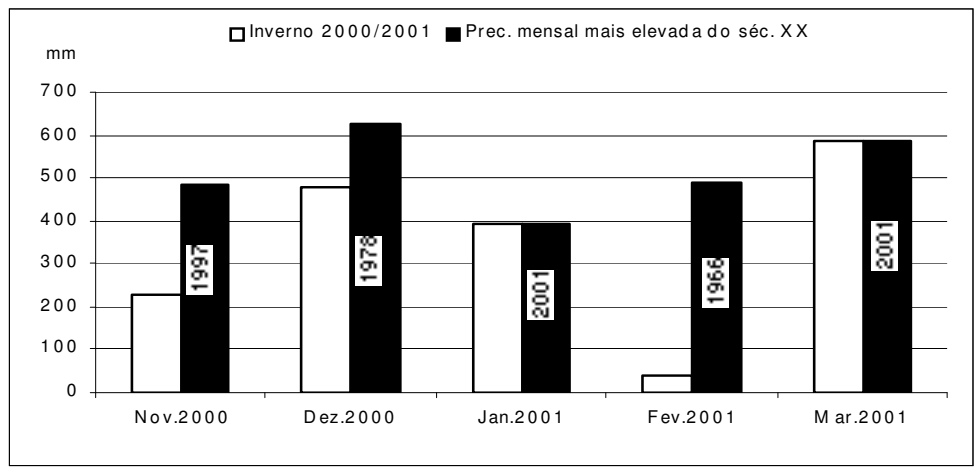

Figura 11. "Excepcionalidade" da precipitação durante o Inverno 2000/2001.
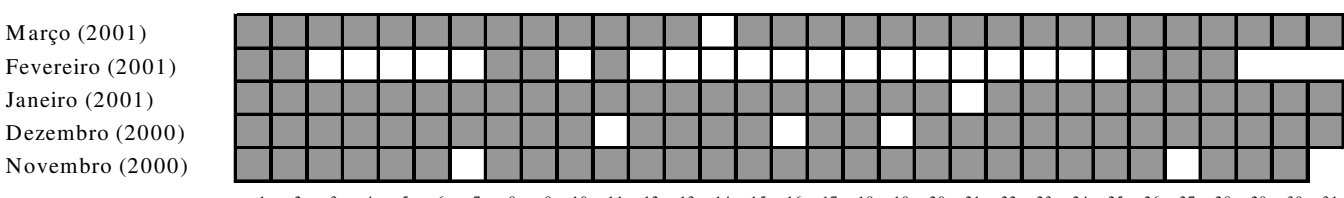

dias com chuva

134 dias com chuva $(83 \%)$

27 dias sem chuva ( 20 foram em Fevereiro)

Figura 12. Sequência de dias com precipitação, no Porto SP, entre Novembro de 2000 e Março de 2001.

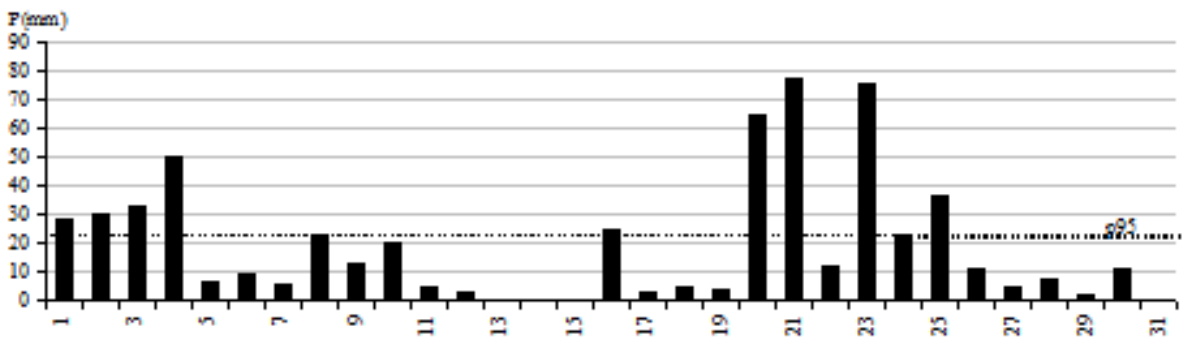

Figura 13. Total diário de precipitação em Março de 2001 no Porto SP

Além da elevada frequência de dias com precipitação, convém notar, também, que Janeiro e Março de 2001, registaram uma considerável ocorrência de totais diários bastante elevados (Figura 14).
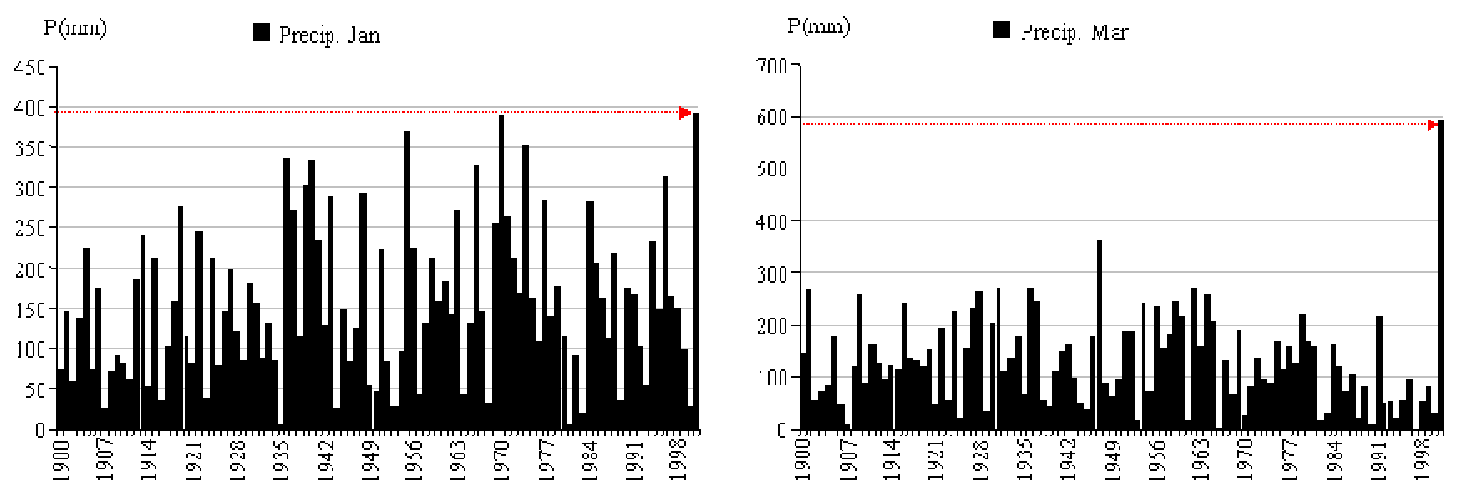

Figura 14. Totais mensais de Janeiro e Março no Porto SP 
Mais de 11 dias de Março de 2001, assistiram à queda de grandes quantidades de precipitação. Apenas, em 1947, havia ocorrido um número semelhante, quando foram registados 7 dias com mais de 20,8mm (percentil 95).

Dois dos três dias de Março com maior precipitação do século aconteceram em 2001 (dia 21 com 76,8 mm e dia 23 com 75, $4 \mathrm{~mm}$ ). O dia de Março mais chuvoso, de que há registo, ocorreu, porém, em 1979 (80,7 mm).

Apesar de se incluírem no período mais pluvioso do ano, não é comum, nem em Março, nem em Janeiro, a precipitação diária ultrapassar os $10 \mathrm{~mm}$. Todavia, em 2001, Janeiro e Março registaram-se 16 dias com mais de $10 \mathrm{~mm}$ de chuva.

\section{O Inverno de 2004-2005}

O Inverno de 2004-2005 foi descrito por diversos actores como um episódio catastrófico de seca de grande gravidade. Contudo, quando observamos a série de mais de 100 anos de registos de precipitação percebemos que o período 2004-2005 não foi o que registou o menor total de precipitação anual, nem o total mais baixo no período húmido ou no período seco do ano (Figuras 6, 10 e 15 e Quadro II).

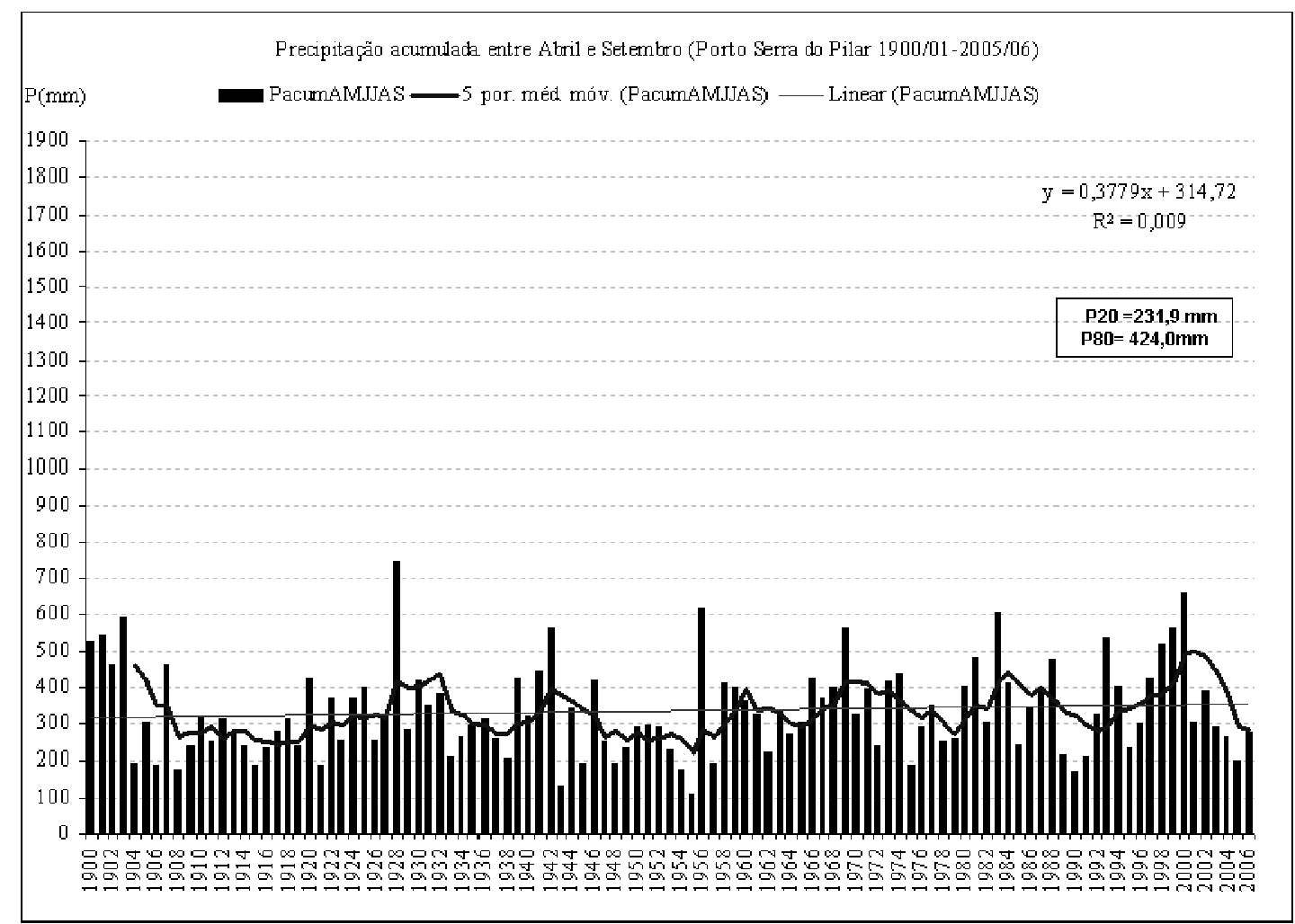

Figura 15. Precipitação acumulada entre Abril e Setembro na estação de Porto Serra do Pilar (1900-2006). 


\begin{tabular}{|l|r|}
\hline Out-04 & $5^{\circ}$ mais chuv oso desde 1900 \\
\hline Nov-04 & $\mathbf{1 8}^{\circ}$ mais seco desde 1900 \\
\hline Dez-04 & $18^{\circ}$ mais seco desde 1900 \\
\hline Jan-05 & $3^{\circ}$ mais seco desde 1900 \\
\hline Fev-05 & $6^{\circ}$ mais seco desde 1900 \\
\hline Mar-05 & $33^{\circ}$ mais seco desde 1900 \\
\hline
\end{tabular}

Quadro II. Posição na série de precipitação mensal de Porto Serra do Pilar (1900-2006).

Como sabemos a seca é uma catástrofe muito peculiar porque tem uma progressão muito lenta e imperceptível que se vai instalando sem ser detectada. A sua definição é diversa (meteorológica, hídrica, política, etc.) consoante o objectivo do investigador e a instituição de referência (Figura 17). Mesmo a definição de seca meteorológica é varia consoante as instituições e os objectivos pretendidos com a avaliação da sua expressividade.

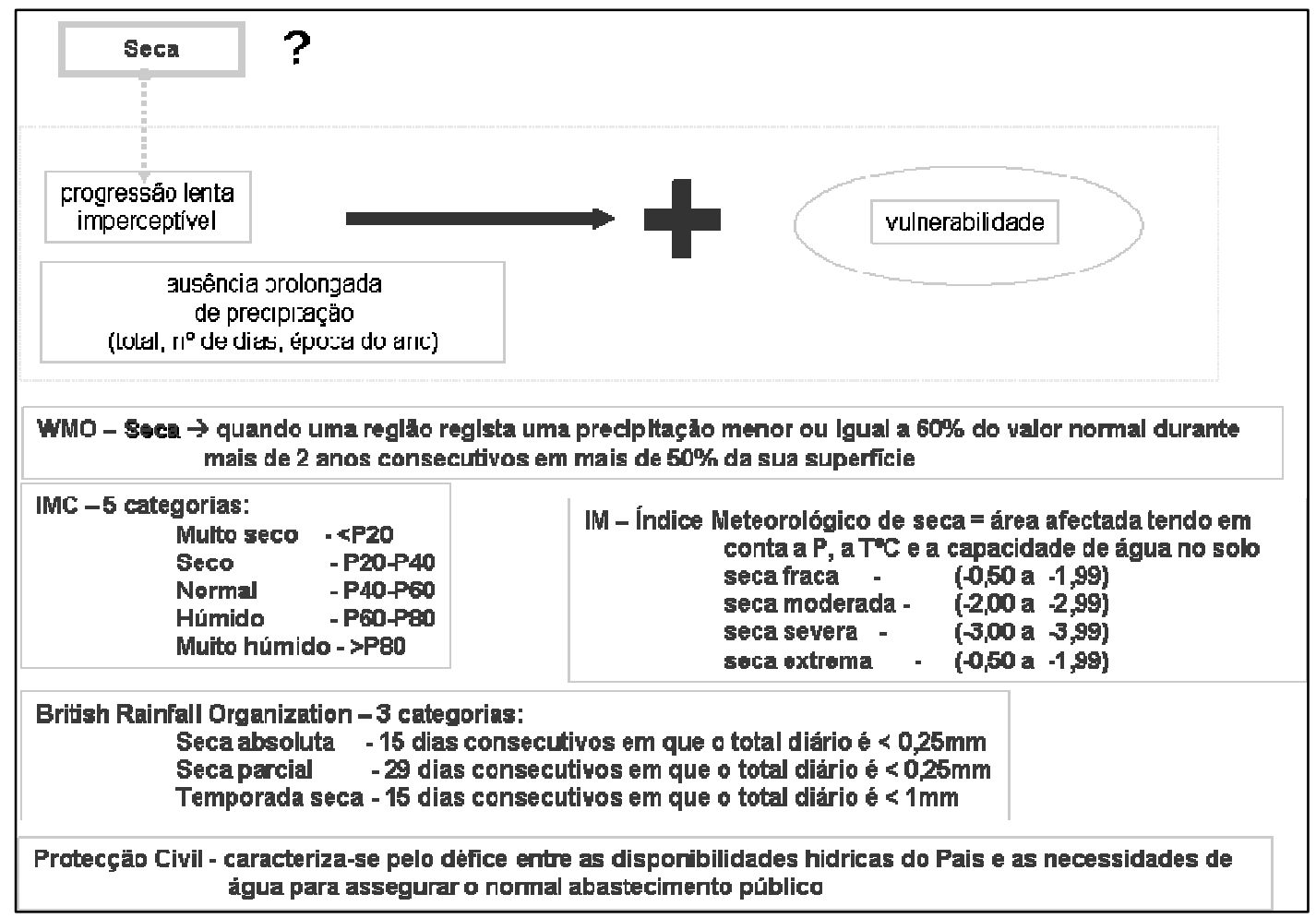

Figura 17. Algumas características e definições de seca meteorológica.

Embora o PDSI (IM, 2005) nos informe da severidade extrema que entre Maio e Setembro de 2005 afectou Portugal (Figura 18), e a análise das sequências de dias sem precipitação no período habitualmente húmido Outubro a Março - evidencie que $68 \%$ dos dias foram secos no Porto-Serra do Pilar (Figura 19), não se tratou de um episódio único à escala do século (Figura 15 e Quadro II). 


\begin{tabular}{|c|c|c|c|c|c|c|c|c|c|c|c|c|}
\hline \multirow[b]{2}{*}{$\begin{array}{l}\text { Classes de } \\
\text { seca }\end{array}$} & \multicolumn{12}{|c|}{$\%$ de território afectado $2004 / 05$} \\
\hline & $\begin{array}{c}31 \\
\text { out } \\
04\end{array}$ & $\begin{array}{c}30 \\
\text { nov } \\
04\end{array}$ & $\begin{array}{c}31 \\
\text { dez } \\
04\end{array}$ & $\begin{array}{l}31 \\
\text { jan } \\
05\end{array}$ & $\begin{array}{c}28 \\
\text { fev } \\
05\end{array}$ & \begin{tabular}{|c|}
31 \\
mar \\
05
\end{tabular} & $\begin{array}{l}30 \\
\text { abr } \\
05\end{array}$ & $\begin{array}{c}31 \\
\text { mai } \\
05\end{array}$ & $\begin{array}{c}30 \\
\text { jun } \\
05\end{array}$ & $\begin{array}{l}31 \\
\text { jul } \\
05\end{array}$ & $\begin{array}{c}31 \\
\text { ago } \\
05\end{array}$ & $\begin{array}{l}30 \\
\text { set } \\
05\end{array}$ \\
\hline c. moderada & 5 & 0 & 0 & 0 & 0 & 0 & 0 & 0 & 0 & 0 & 0 & 0 \\
\hline chuva fraca & 47 & 0 & 0 & 0 & 0 & 0 & 0 & 0 & 0 & 0 & 0 & 0 \\
\hline normal & 22 & 1 & 0 & 0 & 0 & 0 & 0 & 0 & 0 & 0 & 0 & 0 \\
\hline fraca & 20 & 47 & 30 & 0 & 0 & 26 & 15 & 4 & 0 & 0 & 0 & 0 \\
\hline moderada & 5 & 47 & 48 & 25 & 23 & 22 & 22 & 28 & 3 & 0 & 0 & 3 \\
\hline severa & 1 & 5 & 20 & 53 & 44 & 28 & 20 & 20 & 33 & 27 & 29 & 36 \\
\hline extrema & 0 & 0 & 2 & 22 & 33 & 24 & 43 & 48 & 64 & 73 & 71 & 61 \\
\hline
\end{tabular}

Figura 18. Índice meteorológico da seca PDSI (IM, 2005).

dias sem precipitação 44 dias sem chuva (24\%)

Março (2001)

Fevereiro (2001)

Janeiro (2001)

Dezembro (2000)

Novembro (2000)

Outubro (2000)

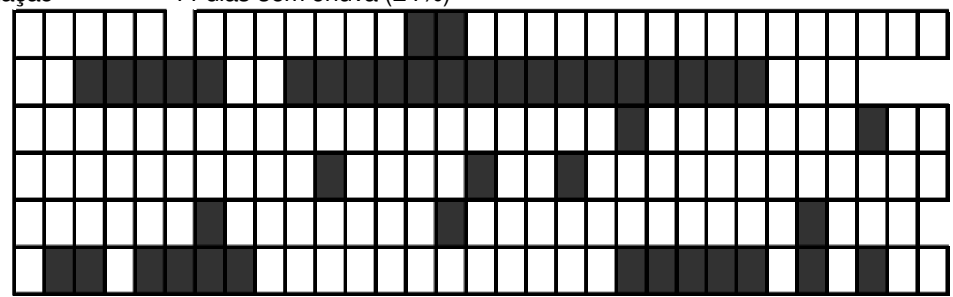

dias sem precipitação Março (2005)

Fevereiro (2005) Janeiro (2005)

Dezembro (2004)

Novembro (2004)

Outubro (2004)
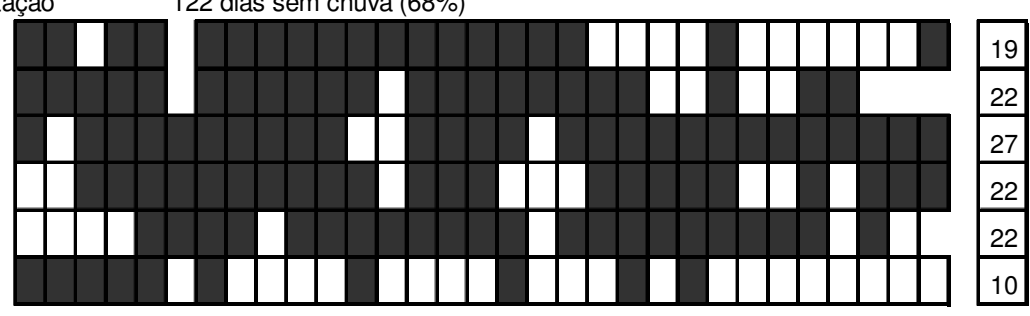

dias sem precipitação

123 dias sem chuva (44\%)

Março (2006)

Fevereiro (2006)

Janeiro (2006)

Dezembro (2005)

Novembro (2005)

Outubro (2005)
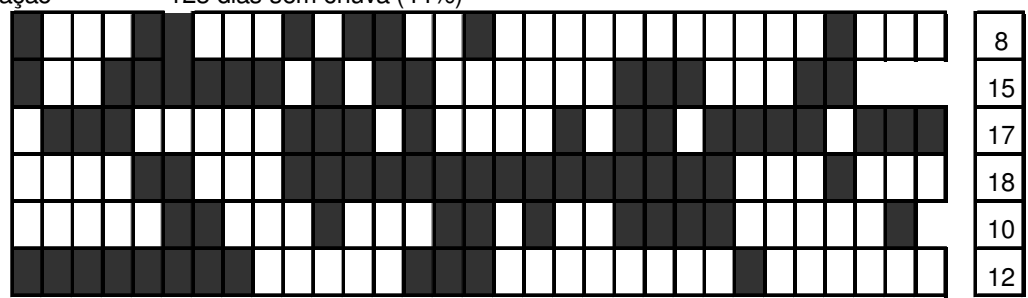

Figura 19. Sequências de dias com e sem precipitação (2000-01, 2004-05 e 2005-06)

\section{CONSIDERAÇÕES FINAIS}

Estes dois exemplos igualmente dramáticos e incompreendidos mas de índole tão diversa (Figura 8), servem para mostrar que enquanto estas expressividades do sistema climático - a precipitação intensa ou a seca - não forem mecanicamente compreendidas dificilmente serão percebidas. $E$, 
continuarão a ser desvalorizadas em qualquer processo de decisão (individual ou colectivo).

Este quadro de grande incompreensão é generalizável a outras escalas espaciais. A importância do(s) risco(s) associados às manifestações de mudança climática global padecem desta mesma patologia - a distância entre os factos e as percepções.

A sociedade está razoavelmente sensibilizada para a possibilidade de vir a ocorrer um aumento da temperatura média do globo mas ainda não consegue imaginar as consequências catastróficas geradas pela impulsividade das respostas que o sistema climático parece preferencialmente adoptar para reagir às tensões (internas e externas).

O argumentário resultante do conhecimento das pressões que estão a afectar o comportamento do subsistema climático local e regional portuense não é suficiente para informar todos os actores envolvidos, nem para os sensibilizar a modificar atitudes de modo a que reduzam a sua vulnerabilidade aos elementos climáticos. A incerteza quanto ao peso relativo de cada uma das relações de causalidade envolvidas nas respostas do sistema climático é uma fragilidade no processo de comunicação em climatologia que, depois, se tem repercutido insistentemente ao nível da acção (Figura 20).

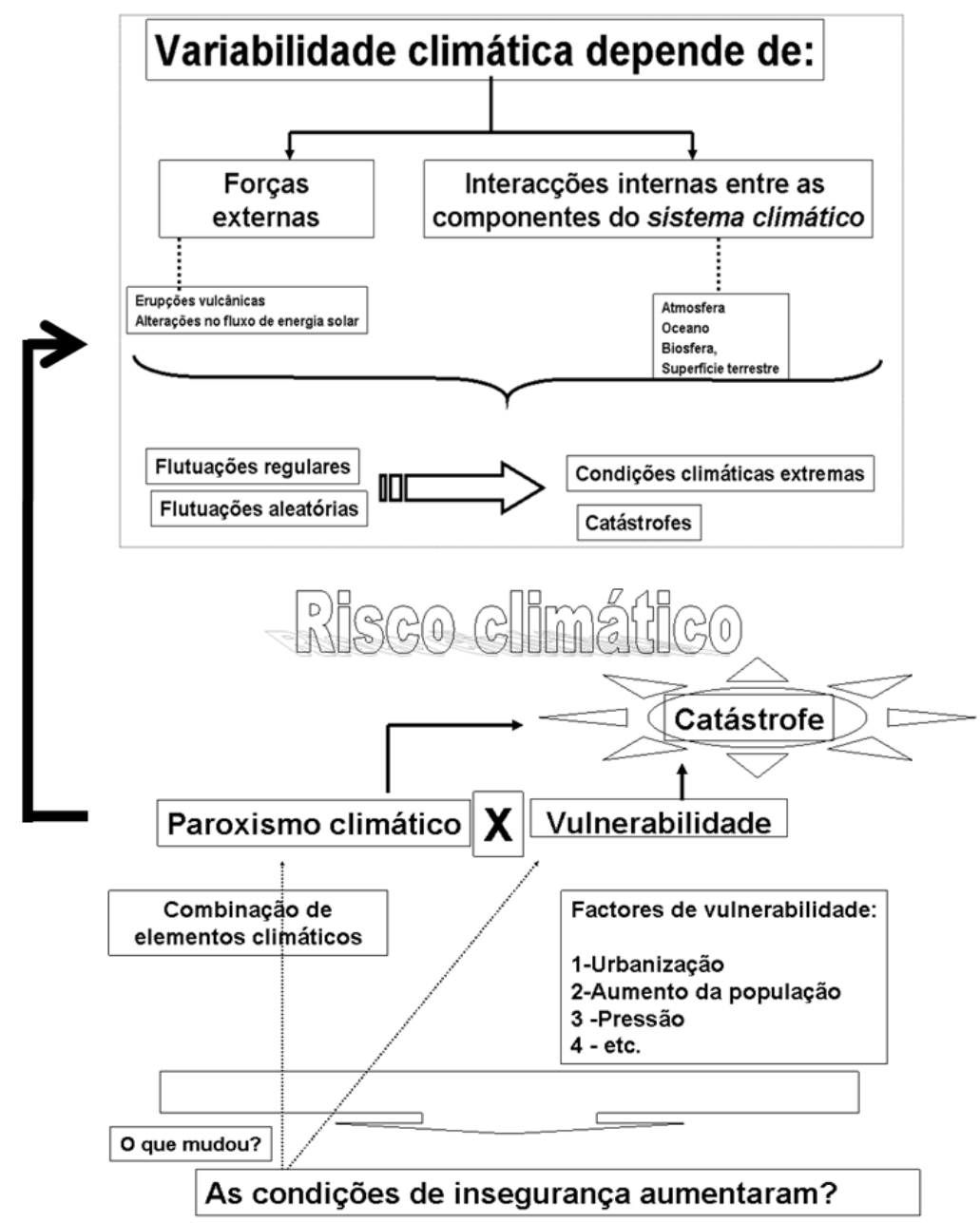

Figura 20. A progressão da vulnerabilidade ao sistema climático. 
Esta lacuna só será colmatada quando os investigadores reorganizarem o discurso científico imprimindo-Ihe também uma vocação pedagógica e uma linguagem própria para estabelecer a comunicação com a sociedade. Primeiro, é necessário clarificar a multiplicidade de factores envolvidos nos cenários de catástrofe climática (Figuras 1 e 3). Depois, é fundamental enquadrar as reflexões em torno dos impactes negativos gerados pelas manifestações de mudança climática numa teia pluridisciplinar onde o conhecimento científico de climatologia é apenas um dentre uma miríade de outros saberes.

A qualificação das ferramentas - conceptuais, metodológicas e instrumentais - disponíveis em climatologia não tem evitado, pelo menos tanto quanto seria desejável, os danos causados pelas secas, precipitações intensas, geadas negras, ondas de calor, vagas de frio, etc.. Isto, pode dever-se ao modo como as sociedades modernas se relacionam com o ecossistema, à forma como percebem e memorizam o comportamento de cada um dos elementos climáticos, à curiosidade desmedida sobre uma realidade intrinsecamente variável, ao enorme incremento de informação sobre o tema e também à dificuldade de comunicação do conhecimento num domínio de grande complexidade como é a climatologia.

Os eventos climatológicos extremos, quando ocorrem, surpreendem uma sociedade que interiorizou a ilusão de absoluta superioridade do Homem relativamente a todas as outras componentes do ecossistema. Os resultados da ciência e as maravilhas da tecnologia animaram o Homem a acreditar que a sua capacidade de domínio sobre o ecossistema é ilimitada e afastaram-no do convívio directo com o ar, a água, o solo, a flora e a fauna. Os contactos passaram a ser filtrados pelos vidros de abrigos cada vez mais sofisticados, interceptados por aprimorados sistemas de drenagem de águas, etc.. Ao modificar a qualidade da observação alteraram-se os processos de memorização e, consequentemente, a percepção das características sistémicas do funcionamento de todas as componentes do Planeta.

\section{REFERÊNCIAS}

ACADEMIA DAS CIÊNCIAS DE LISBOA (2001), Dicionário da Língua Portuguesa Contemporânea, Verbo, Braga.

ALEXANDER, L.V. e PARKER, D.E. (2002), Global and regional climate in 2001 in Weather, n057, Royal Meteorological Society, London, 2002, p. 328 a 340. http://www.catchword.com/rms/00431656/v57n9/contp1-1.htm

ALMENDROS COCA M; FERNÁNDEZ GARCIA, Felipe (1996) La precipitation y el viento como riesgos climáticos urbanos: el caso de Madrid" in Territorium, 3, Minerva, Coimbra, p. 25 a 34.

BLAIKIE, Piers et al.(1994) At Risk - Natural Hazards, people's vulnerability and disasters, Routledge, London. 
BLÖCHLIGER, Hansjörg, NEIDHÖFER, Frank (1999) Effects of Extreme Precipitation Events, Secrétariat OCCC, ProClim,ed., Berne, http://www.proclim.unibe.ch

BOUCHER, Keith (1999) Global warming, in Applied Geography: principles and Practice, Routledge, London.

BRANDÃO, Claudia et al (2001) Análise de fenómenos extremos: precipitações intensas em Portugal continental, Direcção dos Serviços de Recursos Hídricos, Lisboa. http://snirh.inag..pt/snirh/estudos_proj/main.nav.fr.html

BURROUGHS, William et al (1999) Observar o tempo, Edições Atena, São Pedro do Estoril, Lisboa.

CHANGNON, Stanley A., CHANGON, David (1999) Record-Hight Losses for Weather Disasters in the United states durind the 1990s: How Excessive and Why? in Natural Hazards, n018, Kluwer Academic Publishers, Netherlands, p. $287 a 300$.

CHANGNON, Stanley e HEWINGS, Geoffray (2001) Losses from Weather Extremes in the U.S. in Natural Hazards Review, vol2, n03, ASCE, p. 113 a 123.

CONTI, José Bueno (2002) Riscos Naturais na Região Tropical Brasileira in Territorium, no9, Minerva, Coimbra, p. 117 a 122

FERNANDEZ GARCIA, Felipe (1995) Manual de Climatologia Aplicada - Clima, Medio Ambiente y Planificacion, Editorial Sintesis, Madrid.

Ganho, N., Monteiro, A. (1989) Nota sobre a anomalia climática de 1 de Junho a 10 de Julho de 1988 em Portugal Continental, Biblos, vol.LXV, Coimbra, p.165-188.

GANHO, Nuno (2002) O paroxismo pluviométrico de 2000/2001 em Coimbra. Umas notas a montante dos riscos naturais e da crise in Territorium, no 9, Minerva, Coimbra, p.5 a 11

HAQUE, C. Emdad (2000) Risk Assessment, Emergency Preparedness and Response to Hazards: The Case of the 1997 Red River Valley Flood, Canada in Natural Hazards, 21, Kluwer Academic Publishers, 21, Netherlands, p. 225 a 245.

HUME, Mike (1995) Estimating Global Changes in Precipitation in Weather, vol.50, no2, Royal Meteorological Society, London. http://www.cru.uea.ac.uk/cru/papers/

KING, Cuchlaine A. M. (1980) Physical Geography, Blackwell Publishers, Oxford.

KOVACS, Paul e KUNREUTHER, Howard (2001) Managing Catastrophic Risk:Lessons from Canada, Simon Fraser University, Vancouver. http://grace.wharton.upenn.edu/risk/downloads/01-09-HK.pdf 
IPCC (2002) IPCC workshop on changes in Extreme Weather and Climate Events, IPCC, WMO/UNEP, Beijing. http://www.ipcc/pub/pub.htm

IPCC (2007) Fourth Assessment Report: Climate Change 2007, 4 vol., IPCC, WMO/UNEP, Geneva. http://www.ipcc/pub/pub.htm

LAMB, H. (1995) Climate, History and the Modern World" 2nd ed., Routledge, London.

LIMA, Maria Luísa (1997) Contributos para o estudo da representação do risco, $3^{a}$ ed., LNEC, Sector de Artes Gráficas, Lisboa, p. 1 a 102.

MARSH, Terry (1995) Droughts returns to the United Kingdom in Drought Network News, University of Nebraska, Lincoln. http://www.drought.unl.edu/pubs/

MILETI, Dennis, (1999) Disasters by Design - A reassessment of Natural Hazards in the United States, Joseph Henry Press, Washington.

Monteiro, Ana (1990) O Porto e os portuenses no final do séc. $X X$ ou as relações entre os homens e um ecossistema urbano em entropia acelerada, Revista da Faculdade de Letras, Geografia, I Série, vol.VI ${ }_{L}$ Universidade do Porto, 1990, p.5-63.

Monteiro, A., Ganho, N. (1993) A anomalia pluviométrica 1991/92 e 1992/93 no Norte e Centro de Portugal (Porto-Serra do Pilar e Coimbra IGU), Cadernos de Geografia, Instituto de Estudos Geográficos, FLUC, no 12, Coimbra, 1993, p.75-87.

MONTEIRO, Ana (1995) Perceptibilidade, risco e vulnerabilidade em Climatologia - um estudo de caso no Porto" in Territorium, n02, Minerva, Coimbra, p. 51 a 63

MONTEIRO, Ana (2001) A fragilidade de um país que ignora o seu clima: uma reflexão sobre o caos provocado pela chuva no Inverno 2000/2001 na área do Porto in Actas da Aqua 2000, Porto, Universidade Moderna, 2001, p. 1 a 21.

MONTEIRO, Ana (2000) O Clima de Portugal entre 1850 e 1900, Revista da Faculdade de Letras - História, III Série, vol.2, FLUP, Porto, p.167-174.

MONTEIRO, Ana Sistema Climático: uma questão de escala de abordagem na investigação, na comunicação e na acção, UPorto, no16, Junho 2005, p.25

Monteiro, Ana (2007) Depois da tempestade não vem a bonança - uma reflexão em torno da variabilidade da precipitação no Porto (Serra do Pilar), Actas do VIII Colóquio da APMG, Peniche, p.230-231.

PICKERING, Kevin T. e OWEN, Lewis A. (1997) Natural Hazards in Global Environmental Issues. Routledge, London, p. 229 a 347.

PRESS, Frank, SIEVER, Raymond (1998) Understanding Earth, $2^{\text {nd }}$ ed., Freeman, Nova Iorque, p. 472 a 479. 
REBELO, F. (2001) Riscos Naturais e Acção Antropica, Imprensa da Universidade, Coimbra.

REBELO, F. (1997) Risco e crise nas inundações rápidas em espaços urbanos. Alguns exemplos portugueses analisados a diferentes escalas in Territorium, no4, Minerva, Coimbra, p. 29 a 47

ROXO, M. J. e VENTURA, J. (1986) As inundações catastróficas de Novembro de 1983 na Região de Lisboa - Loures in Estudos de Homenagem a Mariano Feio, INIC/IICT/FCSH, Lisboa, p. 391 a 405

SMITH, Keith (1992) Environmental Hazards. Assessing Risk and Reducing Disaster, Routledge, London, p. 3 a 39 e p. 220 a 245.

TOBIN, Graham e MONTZ, Burrel (1997) Natural Hazards: explanation and integration, Guilford Press, New York.

TREMPER, Bruce (1988) "Hazard Catagories in Europe" in The Avalanche Review, vol. 6, n04, A.A.A.

VILELA, Mário (2002) Metáforas do nosso tempo, Coimbra, Livraria Almedina, Coimbra.

WALSH, Rory (1999) Extreme weather events" in Applied Geography: Principles and Practice, Routledge, London, p. 52 a 65.

WEATHER IMPACTS ON NATURAL, SOCIAL AND ECONOMIC SYSTEM (1999) Workshop on Economic and Social Impacts of Climate Extremes: Risk and Benefits", Wise, Amesterdam. http://www.cru.uea.ac.uk/cru/projects/wise/ 